\title{
Comunicação móvel e jogos em espaços híbridos
}

José Carlos Ribeiro, Karla S. Brunet e Thiago Falcão

\section{Resumo}

Os dispositivos móveis de comunicação

potencializaram uma série de práticas sociais que se desenvolvem hoje apoiadas sobre a própria evolução tecnológica. Uma dessas práticas, presente há séculos entre nós, - a de jogar - ganha novos horizontes e significados ao ser aliada a tais dispositivos, modificando-se não só externamente - no modo como se joga, com relação ao quesito regras ou mídia - mas também internamente, em sua própria estrutura lúdica, em sua essência. 0 presente artigo busca um melhor entendimento das estratégias sociais desenvolvidas por atividades lúdicas - na forma de jogos - auxiliadas por dispositivos móveis de comunicação, como celulares, palms, etc., e de como tais atividades interagem hoje com os espaços necessariamente compostos pelo urbano e pelo virtual - espaços híbridos - que permeiam nossa realidade. Palavras-chave

Comunicação móvel. Jogos. Espaços híbridos. Sociabilidade.

\section{José Carlos Ribeiro | j.c.ribeiro@terra.com.br}

Doutor em Comunicação e Cultura Contemporânea pela Universidade Federal da Bahia - UFBA. Professor do Programa de Pós-Graduação em Comunicação e Cultura Contemporâneas na Faculdade de Comunicação da UFBA. Pesquisador do Grupo de Pesquisa em Cibercidade - GPC Ciberpesquisa.

\section{Karla S. Brunet I email@karlabrunet.com}

Pós-doutoranda do GPC - Ciberpesquisa com bolsa FAPESB. Professora Colaboradora do Programa de Pós-Graduação em Comunicação e Cultura Contemporâneas da UFBA.

\section{Thiago Falcão | @@thiagofalcao.net}

Mestrando do Programa de Pós-Graduação em Comunicação e Cultura Contemporâneas da UFBA.

\section{Introdução}

Acostumamo-nos, com o decorrer dos séculos, a ver nossas práticas socioculturais se modificarem, adquirirem novas características, hibridizarem-se, tornarem-se únicas. De certa forma, estivemos, a humanidade, ao longo dos séculos, prontos para essas transformações - às vezes até ávidos para vê-las, para fazer parte delas. Contudo, a velocidade com a qual as Novas Tecnologias da Comunicação (NTC) redefiniram vários dos paradigmas vigentes e cristalizados na estrutura da sociedade ainda é causa - e vai sê-lo por muito mais tempo - de interesse por parte dos vários aspectos da ciência.

Só recentemente, contudo, as manifestações do lúdico através de jogos passaram a ser realmente tocadas por tais tecnologias; há pouco mais de 50 anos surgia o primeiro videogame e há menos de dez anos cunhou-se uma disciplina específica para estudar sua relação com a hipermídia, na figura da ludologia, proposta pelo uruguaio Gonzalo Frasca em 1999.

Tal relacionamento das formas da tecnologia para com os jogos não se limita, porém, somente aos videogames, jogos projetados em uma TV (ou em 
um meio similar) controlados por um jogador: a lógica de "brincar na rua" também foi tocada pelo acesso a esses dispositivos - e como mais uma faceta tocada pela tecnologia, a prática social do brincar também acabou por se modificar. E, embora as mudanças não sejam em um nível universal, ainda assim elas são perceptíveis e precisam ser endereçadas, tratadas, estudadas.

0 fenômeno da mobilidade traz contribuições à estrutura do lúdico - na forma de jogo - que são extremamente relevantes para 0 campo de estudos, tanto da comunicação, que diz respeito aos próprios dispositivos tecnológicos e sua relação para com os espaços, quanto para outros campos, como o da própria ludologia, por exemplo, que vai estudar a essência do jogo enquanto objeto composto de regras e narrativas.

0 objetivo do presente trabalho é, então, traçar um mapeamento de teorias e práticas que envolvem 0 estudo dessa interseção, tentando, assim, traçar algumas considerações sobre como os jogos que não se utilizam necessariamente de um suporte digital podem ser tocados pelo advento da mobilidade - e da tecnologia, assim sendo - e modificar a si próprios, executando, no percurso de tal processo, uma repercussão nas práticas sociais ligadas a tais veículos do lúdico.

\section{0 s jogos e seus espaços representacionais}

0 elemento lúdico, mesmo sendo um grande impulsionador da evolução cultural e social, permeia o planeta há muito tempo. Para Huizinga (2001), o jogo é mais antigo que a própria cultura, já que cultura pressupõe, em sua mínima forma, a formação de uma sociedade. 0 teórico alemão também se debruça sobre a questão dos próprios animais exercerem atividades lúdicas - 0 que descartaria a associação entre tal fenômeno e a necessidade da sofisticação de uma psique, como no caso da raça humana.

Alves (2005) acredita que, com o decorrer do tempo, a humanidade foi associando a figura do jogo simplesmente às atividades de entretenimento, causando, assim, uma absorção dessa premissa pelo senso comum. 0 ato do jogo vai além do simples entreter, uma vez que

0 jogo é mais do que um fenômeno fisiológico ou um reflexo psicológico. Ultrapassa os limites da atividade puramente física ou biológica. É uma função significante, isto é, encerra um determinado sentido. No jogo existe alguma coisa 'em jogo' que transcende as necessidades imediatas da vida e confere um sentido à ação. Todo 0 jogo significa alguma coisa (HUIZINGA, 2001, p. 4).

É apoiando-se sobre esse pensamento que Huizinga (2001) constrói sua idéia de que o jogo se passa num espaço alternativo, separado da realidade; e que, para adentrar o fenômeno do ludismo, o sujeito precisa se desligar de sua vida real e entrar conscientemente em uma atividade considerada 'não séria' - algo muito semelhante ao que Foucault (1967) chamou de heterotopia. Ainda sobre esse entendimento específico da atividade do jogo, Huizinga (2001) acreditava que jogar era uma atividade absolutamente livre de 
interesses materiais, que nenhum lucro poderia provir dos resultados do jogo - que Caillois (1961) costumava classificar de 'atividade improdutiva'.

Os conceitos do teórico, embora importantes para uma aproximação ao campo, hoje não mais são acurados como outrora foram: a transformação de uma série de práticas sociais às quais hoje estamos acostumados também modificou o modo como se joga, o porquê de se jogar e principalmente os 'brinquedos' com os quais o fazemos. Não obstante, toda a idéia de "liberdade de interesses" parece ser, no mínimo, estranha, se considerarmos como os jogos permeiam a sociedade em vários níveis de práticas: entretenimento (o mais comum), trabalho e até mesmo como veículos para a discussão de idéias, para a construção de argumentos e o questionamento de paradigmas.

Esse não-lugar (AUGÉ, 1994) no qual a atividade lúdica se desenvolve recebeu uma terminologia quando, em 2003, Salen e Zimmerman publicaram seu tratado de desenvolvimento e análise generalista dos processos pelos quais o jogo se dá - desde seu suporte analógico, representado em cartas e tabuleiros, por exemplo, à hipermídia, onde se encontra a essência do videogame

(Nesteriuk, 2002) - e passou a ser chamado de Círculo Mágico ${ }^{1}$, sendo inspirado em uma passagem do clássico Homo Ludens, de Huizinga (2001).

Embora 0 círculo mágico seja meramente um dos exemplos de 'lugares de jogo' listados por Huizinga, 0 termo é usado aqui como um ata-
Iho para a idéia de um lugar especial criado por um jogo no tempo e no espaço. 0 fato de que 0 círculo mágico é só isso - um círculo - é uma característica importante deste conceito. Como um círculo fechado, o espaço que ele circunscreve é encapsulado e separado do mundo real. Como um marcador de tempo, o círculo mágico é como um relógio: ele simultaneamente representa um caminho com um começo e fim, mas sem começo e fim. 0 círculo mágico inscreve um espaço que é repetível, um espaço limitado e sem limite ao mesmo tempo. Resumindo, um espaço finito, com possibilidades infinitas (SALEN; ZIMMERMAN, 2003, p. 95).

0 conceito de Salen e Zimmerman (2003), embora de certa forma fundamentado em um dos mais clássicos tratados sobre a relação entre cultura e expressão lúdica, tem sido seriamente questionado nos últimos anos. Cada vez mais, certos jogos - eletrônicos ou que empregam dispositivos eletrônicos para potencializar possibilidades analógicas - rompem com essa idéia de que entraríamos em um espaço separado da realidade. Melhor que isso, acreditamos que tais jogos exerceriam um poder de mediação da realidade, mas sem descartá-la; transformariam o modo como o jogador interage com o sistema - que pode ser aqui digital, num computador, ou mesmo urbano, no caso de uma cidade - sem necessariamente extraí-lo da realidade, como os teóricos citados acreditavam.

Souza e Silva (2004), por exemplo, dá suporte à corrente linha de pensamento à medida que discursa sobre os jogos que se apropriam dos dispositivos móveis para levar às ruas uma nova 
maneira de encarar o lúdico, jogos esses que ela chama de Hybrid Reality Games (HRGs²).

A idéia da autora, ao classificar tais jogos como "de realidade híbrida", é deixar claro que em seu gameplay - momento no qual a atividade se desenvolve - as bordas entre a realidade e 0 ambiente do jogo se borram, se dissolvem, fazendo com que os jogadores precisem trabalhar um agenciamento modificado (MURRAY, 1999), onde eles não estariam necessariamente se utilizando de um personagem pronto, com características próprias, apenas controlando suas ações; há a necessidade, nos jogos pervasivos, de se empregar um agenciamento entre 0 ambiente do jogo e 0 ambiente urbano no qual se encontra, onde tudo isso seria mediado, aqui, pela figura da tecnologia (através do celular, ou de outros dispositivos similares).

É dessa necessidade de agenciamento entre realidade e jogo que surge a terminologia usada pela autora: ela acredita que tais jogos acabam por criar um ambiente necessariamente híbrido, que não é nem o ciberespaço em sua forma pura, como experimentado no processo de ciberflânerie (LEMOS, 2001), por exemplo, nem 0 espaço urbano, pois não só combina, mas também modifica características inerentes aos dois espaços, criando um terceiro, necessariamente composto por formas sociais urbanas, mas fortemente apoiado sobre a necessidade do acesso ao ciberespaço, às redes informacionais virtuais.
A idéia de espaço híbrido de Souza e Silva (2004) parece se aproximar do que Lemos (2007) chama de território informacional:

Por territórios informacionais compreendemos áreas de controle do fluxo informacional digital em uma zona de intersecção entre o ciberespaço e o espaço urbano. 0 acesso e o controle informacional realizam-se a partir de dispositivos móveis e redes sem fio. 0 território informacional não é o ciberespaço, mas o espaço movente, híbrido, formado pela relação entre o espaço eletrônico e o espaço físico (LEMOS, 2007).

É necessário perceber que, no caso dos territórios informacionais, certos teóricos (por exemplo, LEMOS, 2007) acreditam que uma fronteira se desenha - algo que eles chamam de 'bolha' separando o território infundido do fluxo digital do espaço urbano relativamente puro. Tal princípio sugerido pelos autores assemelha-se, em certo grau, à idéia do círculo mágico de Salen e Zimmerman (2003), como manchas espaciais visíveis em um mapa, nas quais pode ou não existir interação entre online e offline. 0 detalhe importante é que a 'bolha informacional' é mais visível porque está atrelada a dispositivos físicos, baseados na tecnologia, que denotam onde ela pode existir. No segundo caso, o do círculo mágico, 0 ato da supressão se modifica de acordo simplesmente com as regras do jogo que está sendo jogado - podendo existir, em potencial, em qualquer lugar. Jogadores de $\mathrm{RPG}^{3}$, principalmente os iniciados na prática do live action, às vezes interpretam seus personagens durante seu dia-a-dia, em qualquer espaço urbano, 
público ou privado; a necessidade é desenvolver um código para identificar quando entrar no gameplay e quando sair dele: aí entraria a idéia do círculo mágico como mediador dessas relações, permitindo a ação do outro nível de agenciamento citado anteriormente.

\section{As ruas como palco}

As ruas como palco para os jogos não é nenhuma novidade, isso sempre aconteceu. Desde criança somos acostumados a brincar nas ruas, fazer delas nosso espaço recreacional. No Brasil, um exemplo comum é quando meninos fecham as ruas para jogar futebol. Partindo de um sentimento de falta desta apropriação das ruas como espaço público e de lazer, vários movimentos de reapropriação das ruas emergiram nas últimas décadas.

Inspirados por movimentos como "Reclaim the streets" (RTS) ${ }^{4}$, muitos artistas e ativistas começaram a desenvolver jogos que utilizam comunicação móvel em espaços urbanos. No começo deste século, as ruas de grandes centros urbanos popularizaram-se como palco para estas brincadeiras e questionamentos artísticos.

0 movimento surgiu na Inglaterra no começo dos anos 90 e tinha a intenção de fazer com que as pessoas deixassem seus carros e se apropriassem das ruas. Uma das primeiras ações propostas pelo grupo foi uma grande festa ilegal realizada em uma das principais ruas de Londres. Charlie Fourier (2003), pseudônimo de um dos integrantes do RTS, conta que levaram 5 meses para conseguir organizar o grupo de mais de 2000 pessoas dispostas a fazerem uma festa no meio da rua, parando o trânsito de carros no centro da cidade. Como a festa era ilegal e a polícia logo apareceria, eles tiveram que planejar cuidadosamente a ação. Outro ponto levado em consideração foi o número de participantes, uma vez que se não houvesse muita gente disposta a participar, a ação não teria sentido.

Como propaganda do movimento, "Reclaim the Streets" usava 0 argumento de que as ruas pertencem às pessoas e não aos carros. 0 site do projeto explica:

As ruas pertencem às pessoas: elas detêm 0 controle da matéria principal da cidade e fazem dela sua própria. É sobre recuperar as ruas como um espaço público inclusivo de um uso privado e exclusivo do carro. Mas nós acreditamos nisto como um princípio mais amplo, pegando de volta coisas que nos foram excluídas dentro do capitalismo e retornando os retornando ao uso coletivo comum. ${ }^{5}$ (tradução nossa)

Outro ativista, John Jordan (2002, p. 352), em seu artigo sobre as manifestações nas ruas de Londres,

RPG é a sigla para Role Playing Game - Jogo de Interpretação de Papéis -, jogo onde jogadores constroem seus personagens e passam a interpretá-Ios em uma narrativa criada anteriormente por um jogador que exerce uma função diferente de todos os outros, conhecido como 'mestre'. A narrativa do RPG é, então, influenciada pelas ações e pensamentos dos jogadores/personagens e se constrói dinamicamente. Fonte: <http://pt.wikipedia.org/wiki/Role_Playing_Game>.

No Brasil "Reclaim the streets" é conhecido como o movimento de "Recuperação das ruas".

URL do site do movimento: <http://rts.gn.apc.org/prop10.htm>. 
fez um depoimento a respeito das ações afirmando:

"Este era um teatro que eu nunca tinha visto antes, um teatro em uma escala que não caberia em uma ópera". Jordan (2002, p. 352) segue dizendo que esse era um espetáculo onde eles é que tinham o controle, "para o qual nós montamos o palco, providenciamos os atores e convidamos o estado para estar em nossa peça, jogar no nosso jogo". Nesse texto, 0 autor faz referência ao teatro e jogo como parte das manifestações pretendidas pelos ativistas.

Com o movimento RTS, as ruas foram palcos de festas e teatros participativos, lugares onde a audiência e o público se misturavam, revelando formas muito parecidas com as preconizadas pelo Teatro Invisível (THOMPSON; SHOLETTE et al., 2004). Proposto por Augusto Boal (1998), Teatro Invisível é uma forma de teatro em lugares não esperados, muitas vezes feito nas ruas, onde 0 público não sabe se o que está acontecendo é uma encenação ou um ato corriqueiro. Considerado um teatro de guerrilha e de provocações, o Teatro Invisível sugere práticas que são muitas vezes propostas para levantar questionamento ou ações por parte de quem está no local.

Esse tipo de inquietação por parte dos transeuntes que ocorre no Teatro Invisível também pode ser observado nos jogos. Em uma versão do jogo "Can you see me now?"' realizado em uma parte da cidade de Barcelona durante o ArtFutura 20047, o gameplay desempenhado simultaneamente por jogadores online e no espaço físico fez com que quem estava "passando", ao não entender o que acontecia, parasse para ver o que era. Os jogadores nas ruas foram muitas vezes interrompidos em sua jogada por pessoas que caminhavam nas calçadas, pelas ruas obstruídas e apertadas, ou carros em movimento.

A principal idéia do movimento RTS era ir contra a preponderância do carro, considerando este um representante da cultura consumista capitalista. "Explicitamente anti-carro, muito do ímpeto do RTS era recuperar o espaço público da rua: (re)criar uma locação geográfica ou uma esfera pública baseada na comunidade"(tradução nossa), salienta Wendy Maples (2000, p. 143). Com 0 passar do tempo o movimento foi tomando outras proporções, grupos de ativistas em outras cidades da Europa e América do Norte começaram a usar a terminologia para definir diversos movimentos de retomada das ruas. A expressão passou a ter uma conotação bem mais ampla, transformando quase que qualquer ação ou performance no espaço público urbano como uma autêntica representação do movimento. Logo, muitos jogos com tecnologia móvel também usaram a bandeira do RTS para justificar sua conquista das ruas.

\section{Comunicação móvel como ferramenta}

0 uso da tecnologia móvel como ferramenta para jogos em espaços urbanos é cada vez mais

URL do projeto: <http://www.canyouseemenow.co.uk/v2/>. No jogo "Can you see me now?" jogadores, munidos de GPS e palmtop, correm pela cidade tentando localizar os jogadores online. 
comum - celulares, Bluetooth, GPS, Wi-fi são instrumentos comumente usados para realizar as tarefas e seguir as regras dos jogos. Em jogos como "Can you see me now?", "Manhattan Story Mashup", "Shoot me if you can"10, "Pirates!"11 $\mathrm{e}$ "Cruel 2 B Kind"12, a mobilidade proporcionada por esses aparatos faz com que a intervenção urbana seja mais ágil e precisa.

Aqui, o celular pode ser considerado como a principal ferramenta dessa mobilidade. Com sua qualidade multi-uso, podemos tanto produzir como receber informações. É um único aparelho que grava áudio, vídeo, faz fotos, envia e recebe arquivos, escreve textos, conecta com a internet e proporciona uma comunicação oral.

Paul Levinson (2004), no livro "Cellphone: the story of the world's most mobile medium and how it has transformed everything!", faz uma retrospectiva das ferramentas móveis. 0 autor exemplifica com 0 instrumento usamos para escrever como a caneta esferográfica, para ler como o livro, para produzir imagens como as câmeras portáteis da Kodak, para escutar música como os rádios de pilha e 0 walkman, e, ao final, chega a uma conclusão de que o celular é a mídia modelo desta mobilidade. Segundo Levinson (2004, p. 52):

0 celular é hoje em dia 0 epítome da mobilidade em mídia porque ele permite tanto a recepção (como 0 livro e o rádio transistor) quanto a produção (como a câmera Kodak), proporciona isto imediatamente e a longa distância (como o radio transistor), e proporciona esta interatividade (como nenhum meio móvel anterior). (tradução nossa)

\section{Ao mesmo tempo Castells (CASTELLS;}

FERNANDEZ-ARDEVOL et al., 2007, p. 185)

considera que a "comunicação sem fio proporciona uma poderosa plataforma para autonomia política na base de um canal independente de comunicação autônoma de pessoa para pessoa"13. Realmente, isso pode ser evidenciado em muitos dos jogos com intuito de recuperar as ruas. Contudo, em sociedades onde as empresas detentoras dessas tecnologias de comunicação formam parte de um oligopólio de mercado (como no Brasil), essa realidade de autonomia não se mostra possível. Tendo em vista os altos custos da telefonia celular no Brasil, percebe-se que, por mais que o número de celulares seja grande ${ }^{14}$, existem pouquíssimas

URL do jogo: <http://www.blasttheory.co.uk/bt/work_cysmn.html>.

URL do jogo: <http://www.storymashup.org>.

10 URL do jogo: <http://www.shootmeifyoucan.net/>.

1 URL de artigo sobre o jogo: <http://www.viktoria.se/fal/publications/play/2001/pirates.interact.pdf>.

12 URL do jogo: <http://cruelgame.com/>.

13 Nossa tradução do original "Wireless communication provides a powerful platform for political autonomy on the basis of independent channel of autonomous communication from person to person."

14 No Brasil em abril de 2008 o número de celulares ativos era de 127.742.000. Fonte: <http://www.iftk.com.br/wordpress/ numero-de-celulares-no-brasil-1277-milhoes.html>. 
práticas de jogos nos espaços urbanos que se utilizem dessas possibilidades.

Embora a prática desse tipo de jogos seja muito pequena no país, o uso do celular como ferramenta de intensificação das relações sociais é algo facilmente observável. Em um artigo sobre os usos sociais da comunicação móvel, Jane Vincent (2004) aponta que a maior utilização dos telefones celulares é para o uso pessoal, para saber sobre amigos e familiares. Diferente do que se pensava, o celular não é prioritariamente um meio de comunicação para negócios, seu uso para "manter conectados" amigos ou familiares ultrapassou o uso com clientes e empresas. Em uma pesquisa empírica realizada para 0 UMTS Forum $^{15}$, Vincent (2004) mostrou que grande porcentagem dos usuários de celular o consideram importante para utilizar para: emergência, falar o que estão fazendo, cuidar uns dos outros, saber o que os outros estão fazendo e conversar. Essa pesquisa mostra o celular com uma ferramenta pessoal que ajuda a fortalecer os laços sociais. Tendo em vista o celular como objeto fortalecedor de redes sociais, vários jogos foram criados usando a tecnologia para experimentar com esse tipo de relação. Mas como esses aspectos e características dos dispositivos comunicacionais móveis (em especial, os telefones celulares) se apresentam de fato como facilitadores de trocas sociais?

\section{5 "Cruel 2 B Kind": um jogo vivenciado em espaços híbridos}

Escolhemos, para exemplificar a carga teórica discutida previamente, traçar uma análise do jogo "Cruel 2 B Kind", desenvolvido por Jane McGonigal (Avant Games) e por Ian Bogost (Persuasive Games), que se baseia em antigos jogos infantis - cujos nomes variam geográfica e socialmente - mas se apropria das regras para modificá-lo e imprimir um significado em seu gameplay.

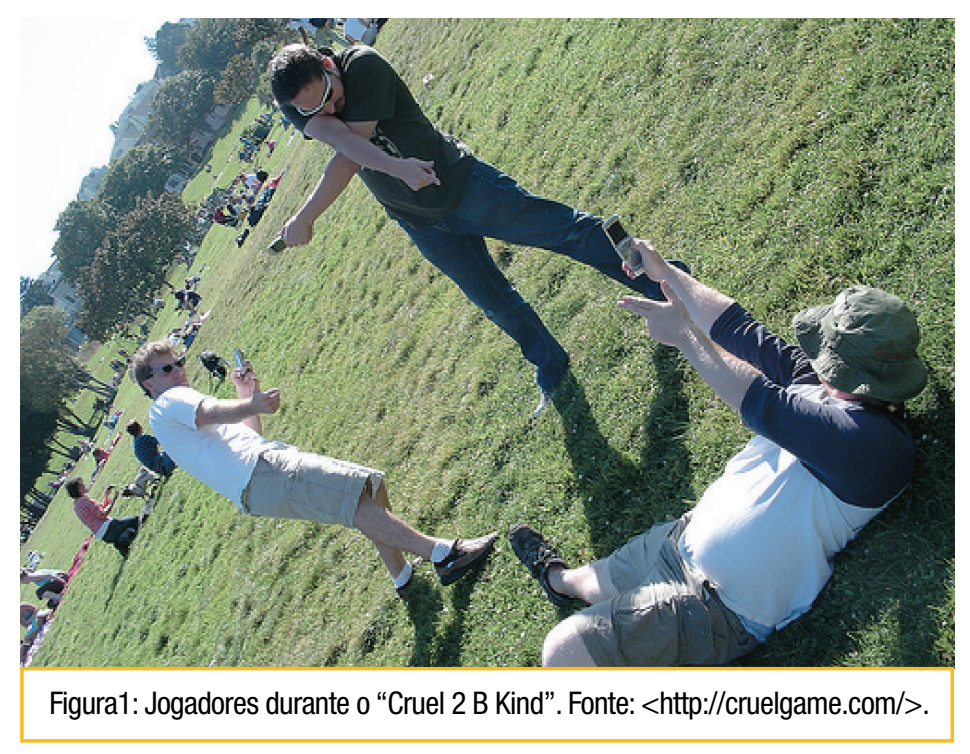


No começo do jogo, cada time de jogadores, variando entre uma, duas e três pessoas por time, recebe três "armas secretas", que na verdade são atos de gentileza e benevolência esses atos serão usados para "matar"/desabilitar - outros jogadores/times, que no momento vão entregar ao "assassino" seu tesouro uma peça sem grande valor monetário que representa unicamente o participante no jogo; os criadores sugerem coisas como "um livro usado interessante, doces exóticos, dinheiro estrangeiro ou um cartão postal com um haicai original no verso" (BOGOST; MCGONIGAL, 2008). No momento que o tesouro for entregue, o jogador "assassinado" entra para o time dos "assassinos" e passa a jogar com eles.

0 processo, então, se repete até que só sobrem dois times, e 0 jogo finalmente chega ao fim quando: (1) os grupos engajam um ao outro e se "matam", no que os autores chamam de "clímax banho-de-sangue" (climactic bloodbath); ou (2) o tempo do jogo, pré-definido no começo, acaba, e o jogo fica sem vencedores. Em ambos os finais, os maiores assassinos - com mais mortes, ou com mortes mais criativas - são homenageados com títulos especiais. Como o jogo é jogado em ambientes urbanos e públicos, "inocentes" - pessoas que não estão cientemente jogando podem ser pegos no fogo cruzado, mas os autores explicam que: "num jogo onde as armas são atos de gentileza, isso não vai fazer muita diferença"16.
Entre as diversas características que se apresentam, e que se aproximam mais claramente das reflexões propostas por este artigo, estão aquelas que potencializam as trocas sociais efetivadas pelos participantes. Seja pela "indicação" de inserção em "equipes" compostas de dois ou mais participantes, seja pela "obrigatoriedade" do desenrolar do jogo ser efetivado sempre em espaços públicos e abertos, o que se percebe é a estimulação de processos interacionais. Embora ambas sejam derivadas de imposições colocadas pelas regras iniciais do jogo e visem basicamente organizar a realização de contatos sociais entre as pessoas, cada uma delas promove de maneira diferenciada acordos que, ao serem seguidos, potencializam as articulações sociais através do uso das tecnologias comunicacionais móveis.

Na primeira situação imposta, a noção de atividade grupal colaborativa se configura, formatando condutas sociais que devem ser seguidas em consonância com os demais participantes da equipe em que estão inseridos. Assim, cria-se uma interdependência entre seus membros, onde cada comportamento individual deve seguir as estratégias traçadas previamente (no caso, a maneira adequada de utilização das armas escolhidas, a ação em conjunto etc.), a fim de alcançar os objetivos e interesses comuns (o "assassinato" de participantes das equipes adversárias). 0 interessante é que tais 
comportamentos sociais efetivados recebem a vigilância não apenas dos demais membros da equipe quanto ao acordado, mas também, e principalmente, de um sistema mestre (conduzido por participantes que centralizam as informações), localizado em espaço geográfico diferente (e distanciado) do ambiente onde a parte visível do jogo se desenrola. Ou seja, há um sistema de controle à distância, o qual deverá ser notificado sobre as diversas ações (ataque bem sucedido, reconfiguração dos componentes etc.) efetivadas pelas equipes. Nesse aspecto é que se manifesta a presença da comunicação móvel (em particular, o uso da telefonia celular) como elemento que propicia e viabiliza o mapeamento e 0 gerenciamento das diversas fases do jogo, haja vista que essas informações trocadas são feitas através da circulação (envio e recepção) de mensagens SMS para o sistema mestre.

Na segunda situação, a da vivência lúdica se apresentar necessariamente nos espaços públicos, verifica-se a exploração do ambiente como palco aberto dos acontecimentos, onde diversas pessoas, não integrantes do jogo, transitam de forma casual, anônimas e completamente alheias aos propósitos norteadores da experiência (conforme 0 sugerido pelo Teatro do Invisível). Nesse contexto, uma peculiaridade se apresenta: a possibilidade de inusitadas trocas sociais entre participantes e não participantes, haja vista que não há, de maneira visível, características que distingam um participante de um mero transeunte do momento naquele espaço público. Logo, em tese, os adversários podem ser qualquer um, 0 que, por sua vez, possibilita a emergência de dois tipos de trocas sociais: (1) entre jogadores "conscientes", (2) e entre aqueles "conscientes" e os "não conscientes" da existência de um jogo naquele local. Ora, esse aspecto, associado com outro presente no jogo de uso de práticas sociais não convencionais (no caso, elogios direcionados) para "atacar" e "render" o "inimigo", pode provocar diversas situações inusitadas. Sendo assim, um "ataque", feito a partir de elogios direcionados a potenciais jogadores - que o jogador em questão não conhece, não sabe se estes estão no jogo -, promoverá possivelmente uma situação social constrangedora, visto que o uso de elogios gratuitos (sem razão aparente) a pessoas desconhecidas não faz parte das práticas socioculturais costumeiras.

Também no dado exemplo, a utilização da comunicação móvel se mostra imprescindível para 0 "andamento" do jogo, uma vez que sem ela a tentativa de deslocamentos articulados e "ataques" direcionados a "suspeitos" que sejam de fato participantes seria extremamente dificultada. 0 aparato tecnológico facilita 0 trânsito coordenado e a troca de informações estratégicas entre as pessoas componentes das equipes, evitando assim a desagradável situação de abordar alguém com um comportamento social inadequado.

Outro aspecto que sobressai no jogo analisado é a possibilidade de mudança de papéis sociais 
durante 0 desenrolar das atividades lúdicas.

De acordo com as regras estabelecidas, os participantes que são "mortos" por um grupo adversário, a partir daquele momento, são absorvidos pelos seus "assassinos", passando a fazer parte da equipe, o que faz com que os componentes "perdedores" efetivem uma troca de seu papel social de adversários (no primeiro momento) para companheiros e colaboradores (no segundo momento) do grupo dos componentes "vencedores". 0 que chama atenção, mais uma vez, é que tais procedimentos seriam extremamente dificultados se não houvesse a possibilidade de uma coordenação efetivada a partir de uma central de informações (sistema mestre), localizada à distância e contatada pela circulação de SMSs trocados pelos participantes.

\section{Considerações finais}

0 espaço híbrido, empregado por diversos autores (CHARITOS, DIAMANTAKI et al.; MCQUIRE, 2006; SANT, 2006; SILVA, 2006; MIRANDA, 2007) como o hibridismo entre 0 virtual e o físico, é 0 local onde jogos como "Cruel 2 B Kind" ocorrem, um espaço físico da cidade com parque, calçadas, bancos, misturado com o espaço hertzian $0^{17}$ dos campos eletromagnéticos que conectam os celulares.

Tomando como base a teoria de Steve Harrison e Paul Dourish (1996), que diferencia espaço de lugar, podemos dizer que o jogo "Cruel 2 B Kind" transcorreu em um lugar híbrido, e não somente em um espaço híbrido. Os autores diferenciam as duas terminologias afirmando:

Fisicamente, um lugar é um espaço que é reforçado de entendimentos de apropriação comportamental, expectativas culturais e assim por diante. Nós nos localizamos no "espaço", mas agimos no "lugar". Além do mais, "lugares" são espaços que possuem valor. A distinção é mais ou menos como entre a de "casa" e de "lar", a casa nos mantém abrigados do vento e da chuva, mas o lar é onde vivemos. (tradução nossa)

Nesse sentido, o lugar é o espaço com os significados sociais, culturais e funcionais. 0 comportamento dos atores do jogo "Cruel 2 B Kind" trabalham com esses significados impostos pelo espaço, sendo estes, então, denominados "lugares híbridos".

Como podemos observar, através de uma complexa combinação de redes informacionais, mobilidade e exploração de espaço público, e uso de aparatos tecnológicos comunicacionais móveis, constroem-se possibilidades de ações que visam, em última instância, uma certa reapropriação dos territórios físicos (conforme preconiza o movimento RTS) a partir da mediação dos territórios informacionais. Dito de outro modo, configura-se um verdadeiro espaço híbrido (SOUZA; SILVA, 2006), dissolvido entre as esferas real e virtual, composto de elementos estratégicos 
e informacionais complementares, vivenciados de maneira lúdica, participativa e interativa. De forma semelhante, pode-se perceber a ação do círculo mágico (SALEN; ZIMMERMAN, 2003) como mediador entre as relações entre jogadores, que estão geograficamente dispostos num espaço público, onde qualquer um pode, virtualmente, ser um jogador (ou não) - mas também se verifica a maleabilidade do conceito quando um elogio/"arma" é dirigido a alguém que não está entre os jogadores.

Revela-se, dessa forma, uma expressão potencializada do uso das tecnologias comunicacionais móveis para mediar relações sociais estabelecidas em ambientes públicos e abertos, nos quais se valorizam a mobilidade e 0 dinamismo presentes nestas configurações.

\section{Referências bibliográficas}

ALVES, Lynn. Game over: jogos eletrônicos e violência. São Paulo: Futura, 2005.

AUGE, Marc. Não-lugares: introdução a uma antropologia da supermodernidade. Campinas: Papirus, 1994.

BAUMAN, Zygmunt. Globalization: the human consequences. New York: Columbia University Press. 1998.

BOAL, Augusto. Invisible Theater. In: COHENCRUZ, Jan (ed.). Radical street performance: an international anthology. London: Routledge, 1998. BOGOST, Ian; MCGONIGAL, Jane. Cruel 2 B Kind - About the Game. 2008. Disponível em: <http:// cruelgame.com/about/>. Acesso em: 19 dez. 2008

CAILLOIS, Roger. Les jeux et les hommes. Le masque et le vertige. Cher: Gallimard, 1961 (1967).
CASTELLS, Manuel; FERNANDEZ-ARDEVOL, Mireia. et al. Mobile communication and society: a global perspective. Cambridge: MIT Press. 2007.

CHARITOS, Dimitris.; DIAMANTAKI, Katerina. et al. The emergence of new types of hybrid mobile communication environments and their impact on social life within the urban context. Digital utopia in the media. Disponível em: <http://cicr.blanquerna. url.edu/2005/Abstracts/PDFsComunicacions/vol2/08/ CHARITOS_DIAMANTAKI_GAZI_\%20MEIMARIS. pdf> Acesso em: 12 maio 2008.

FOUCAULT, Michel. Of other spaces, Heterotopias.. Disponível em: < http://foucault.info/documents/ heteroTopia/foucault.heteroTopia.en.html>. Acesso em: 20 fev. 2008.

FOURIER, Charles. Reclaim the Streets: an arrow of hope. Notes from Nowhere. In: We are everywhere: the irresistible rise of global anti-capitalism. London: Verso, 2003.

HARRISON, Steve. e DOURISH, Paul. Re-place-ing space: the roles of place and space in collaborative systems. CSCW'96. Disponível em: <http://www.ics. uci.edu/ jpd/publications/2006/cscw2006-space.pdf> . Acesso em: 30 maio 2008

\section{HUIZINGA, Johann. Homo Ludens: 0 Jogo como}

Elemento da Cultura. São Paulo: Perspectiva, 1950 (2001).

JORDAN, John. The art of necessity: the subversive imagination of anti-road protest and reclaim the streets. In: Duncombe, Stephen (ed.). Cultural resistance reader: a reader. London: Verso, 2002.

LEMOS, André. Ciber-flânerie. In:Fragoso, Suely. et alli. Comunicação na cibercultura. São Leopoldo : Unisinos, 2001

\section{LEMOS, André. Mídia locativa e territórios}

informacionais. Disponível em: <http://www.facom. ufba.br/ciberpesquisa/andrelemos/midia_locativa. pdf>. 2007. Acesso em: 5 fev. 2008 
LEVINSON, Paul. Cellphone: the story of the world's most mobile medium and how it has transformed everything! New York: Palgrave Macmillan. 2004.

\section{MAPLES, William. Queer insights on eco-} action. In: SEEL, B.; PATERSON, M. (ed.). Direct Action in British Environmentalism. New York: Routledge, 2000.

\section{MCQUIRE, Scott. The politics of public space in}

the media city. First Monday. Disponível em: $<\mathrm{http} / /$ repository.unimelb.edu.au/10187/2340>. 2006.

Acesso em: 19 dezembro 2008.

\section{MIRANDA, Maria. Uncertain Spaces: Artists'}

Exploration of New Socialities in Mediated

Public Space. Scan Journal. Disponível em: $<$ http://scan.net.au/scan/journal/display. php?journal_id=101> Acesso em: 28 maio 2008

MURRAY, Janet. Hamlet on the Holodeck. The future of narrative in cyberspace. Cambridge: Mit Press, 1999.

NESTERIUK, Sérgio. A narrativa do jogo na hipermídia: a interatividade como possibilidade comunicacional. 2002. Dissertação (Mestrado em Comunicação e Semiótica) apresentada ao Programa de Pós-Graduação em Comunicação, Pontifícia Universidade Católica - PUC, São Paulo, 2002.

SALEN, Katie. e ZIMMERMAN, Eric. Rules of play: game design fundamentals. Cambridge: MIT Press, 2003.

SANT, Alison. Trace: mapping the emerging urban landscape. Leonardo Electronic Almanac. Disponível em: <http://leoalmanac.org/journal/vol_14/lea_v14_ n03-04/asant.asp>. Acesso em: 22 maio 2008

SOUZA E SILVA, Adriana de. Location based mobile games: blurring the borders between phyisical and virtual spaces. In: Proceedings of inter-society for the electronic arts, 2004. Disponível em: <http://www. isea2004.net/proceedings $>$. Acesso em: 25 julho 2007.
SOUZA E SILVA, Adriana de. Do ciber ao híbrido: tecnologias móveis como interfaces de espaços híbridos. In: ARAUJO, Denize Correa (org.). Imagem (ir)realidade: comunicação e cibermídia. Porto Alegre: Sulina, 2006.

THOMPSON, Nato.; SHOLETTE, Gregory., et al. The interventionists: users' manual for the creative disruption of everyday life. North Adams: MASS MoCA; MIT Press, 2004.

\section{VINCENT, J. The social shaping of the mobile} communications repertoire. In: The journal of Communications Network. Vol 3. Parte 1, Jan-Mar. 2004. 
Mobile communication and games in public spaces

\section{Abstract}

Mobile communication devices have strengthened an amount of social practices that are currently developing supported by the technological evolution. One of these practices, among us for centuries - the practice of playing games - embodies new horizons and meanings by its integration with such devices, transforming itself not only in the exogenous area - in the way we play, related to the structure of rules and media but internally as well, in its own ludic structure, in its essence. The current paper aims to better understand the social strategies developed by these ludic activities - in the form of gameplay - helped by mobile communication devices, like cell phones, palms and so on. It also intends to comprehend how, nowadays, these activities interact with spaces necessarily composed by the urban and by the virtual - the hybrid spaces - which are amid our reality.

\section{Keywords}

Mobile communication. Games. Hybrid spaces. Sociability.

\section{Comunicación móbil y juegos en espacios híbridos}

\section{Resumen}

Los dispositivos móviles de comunicación intensificaran una serie de prácticas sociales que se desarrollaran hoy apoyadas sobre la propia evolución tecnológica. Una de estas prácticas, presente entre nosotros desde hace siglos, - la de jugar - gana nuevos horizontes y significados al ser aliada a tales dispositivos, modificándose no solo externamente - en el modo como se juega, con relación al quesito reglas o media - pero también internamente, en su propia estructura lúdica, en su esencia. El presente artículo busca un mejor entendimiento de las estrategias sociales desarrolladas por actividades lúdicas - en la forma de juegos - auxiliadas por dispositivos móviles de comunicación, como celulares, palms, etc., y de cómo tales actividades interaccionan hoy con los espacios necesariamente compuestos por lo urbano y por lo virtual - espacios híbridos - que entremedian nuestra realidad.

\section{Palabras clave}

Comunicación móvil. Juegos. Espacios híbridos. Sociabilidad. 


\section{Expediente}

A revista E-Compós é a publicação científica em formato eletrônico da Associação Nacional dos Programas de Pós-Graduação em Comunicação (Compós). Lançada em 2004, tem como principal finalidade difundir a produção acadêmica de pesquisadores da área de Comunicação, inseridos em instituições do Brasil e do exterior.
E-COMPÓS I www.e-compos.org.br I E-ISSN 1808-2599

Revista da Associação Nacional dos Programas de Pós-Graduação em Comunicação. Brasília, v.11, n.2, maio/ago. 2008

A identificação das edições, a partir de 2008 passa a ser volume anual com três números.

\section{CONSELHO EDITORIAL}

\section{Afonso Albuquerque}

Universidade Federal Fluminense, Brasil

Alberto Carlos Augusto Klein

Universidade Estadual de Londrina, Brasi

Alex Fernando Teixeira Primo

Universidade Federal do Rio Grande do Sul, Brasi

Alfredo Vizeu

Universidade Federal de Pernambuco, Brasil

Ana Carolina Damboriarena Escosteguy

Pontifícia Universidade Católica do Rio Grande do Sul, Brasil

Ana Silvia Lopes Davi Médola

Universidade Estadual Paulista, Brasil

André Luiz Martins Lemos

Universidade Federal da Bahia, Brasil

Ângela Freire Prysthon

Universidade Federal de Pernambuco, Brasil

Antônio Fausto Neto

Universidade do Vale do Rio dos Sinos, Brasil

Antonio Carlos Hohlfeldt

Pontifícia Universidade Católica do Rio Grande do Sul, Brasil

Arlindo Ribeiro Machado

Universidade de São Paulo, Brasil

César Geraldo Guimarães

Universidade Federal de Minas Gerais, Brasi

Cristiane Freitas Gutfreind

Pontifícia Universidade Católica do Rio Grande do Sul, Brasil

Denilson Lopes

Universidade Federal do Rio de Janeiro, Brasil

Eduardo Peñuela Cañizal

Universidade Paulista, Brasil

Erick Felinto de Oliveira

Universidade do Estado do Rio de Janeiro, Brasil

Francisco Menezes Martins

Universidade Tuiuti do Paraná, Brasil

Gelson Santana

Universidade Anhembi/Morumbi, Brasil

Hector Ospina

Universidad de Manizales, Colômbia

leda Tucherman

Universidade Federal do Rio de Janeiro, Brasil

Itania Maria Mota Gomes

Universidade Federal da Bahia, Brasil

Janice Caiafa

Universidade Federal do Rio de Janeiro, Brasil

Jeder Silveira Janotti Junior

Universidade Federal da Bahia, Brasil
John DH Downing

University of Texas at Austin, Estados Unidos

José Luiz Aidar Prado

Pontifícia Universidade Católica de São Paulo, Brasil

José Luiz Warren Jardim Gomes Braga

Universidade do Vale do Rio dos Sinos, Brasi

Juremir Machado da Silva

Pontifícia Universidade Católica do Rio Grande do Sul, Brasil

Lorraine Leu

University of Bristol, Grã-Bretanha

Luiz Claudio Martino

Universidade de Brasília, Brasil

Maria Immacolata Vassallo de Lopes

Universidade de São Paulo, Brasil

Maria Lucia Santaella

Pontifícia Universidade Católica de São Paulo, Brasil

Mauro Pereira Porto

Tulane University, Estados Unidos

Muniz Sodre de Araujo Cabral

Universidade Federal do Rio de Janeiro, Brasil

Nilda Aparecida Jacks

Universidade Federal do Rio Grande do Sul, Brasil

Paulo Roberto Gibaldi Vaz

Universidade Federal do Rio de Janeiro, Brasil

Renato Cordeiro Gomes

Pontifícia Universidade Católica do Rio de Janeiro, Brasil

Ronaldo George Helal

Universidade do Estado do Rio de Janeiro, Brasil

Rosana de Lima Soares

Universidade de São Paulo, Brasil

Rossana Reguillo

Instituto Tecnológico y de Estudios Superiores do Occidente, México

Rousiley Celi Moreira Maia

Universidade Federal de Minas Gerais, Brasil

Sebastião Carlos de Morais Squirra

Universidade Metodista de São Paulo, Brasil

Simone Maria Andrade Pereira de Sá

Universidade Federal Fluminense, Brasil

Suzete Venturelli

Universidade de Brasília, Brasil

Valério Cruz Brittos

Universidade do Vale do Rio dos Sinos, Brasil

Veneza Mayora Ronsini

Universidade Federal de Santa Maria, Brasil

Vera Regina Veiga França

Universidade Federal de Minas Gerais, Brasil

\section{COMISSÃO EDITORIAL}

Ana Gruszynski I Universidade Federal do Rio Grande do Sul, Brasil João Freire Filho I Universidade Federal do Rio de Janeiro, Brasil Rose Melo Rocha I Escola Superior de Propaganda e Marketing, Brasil

\section{CONSULTORES AD HOC}

Aníbal Bragança I Universidade Federal Fluminense, Brasil Gisela Castro I Escola Superior de Propaganda e Marketing, Brasil

Gislene Silva I Universidade Federal de Santa Catarina, Brasil

Maria Helena Weber I Universidade Federal do Rio Grande do Sul, Brasil

Rosana de Lima Soares I Universidade de São Paulo, Brasil

Tania Hoff I Escola Superior de Propaganda e Marketing, Brasil

REVISÃO DE TEXTO E TRADUÇÃo I Everton Cardoso

ASSISTÊNCIA EDITORIAL E EDITORAÇÃO ELETRÔNICA I Raquel Castedo
COMPóS I www.compos.org.br

Associação Nacional dos Programas de Pós-Graduação em Comunicação

Presidente

Erick Felinto de Oliveira

Universidade do Estado do Rio de Janeiro, Brasil erickfelinto@uol.com.br

Vice-presidente

Ana Silvia Lopes Davi Médola

Universidade Estadual Paulista, Brasil

asilvia@faac.unesp.br

Secretária-Geral

Denize Correa Araújo

Universidade Tuiuti do Paraná, Brasil

denizearaujo@hotmail.com 